\title{
REVIEW
}

\section{Recognition and management of neuropsychiatric complications in Parkinson's disease}

\author{
Florian Ferreri, Catherine Agbokou, Serge Gauthier
}

\section{ABstraCt}

Parkinson's disease is primarily considered a motor disease characterized by rest tremor, rigidity, bradykinesia and postural disturbances. However, neuropsychiatric complications, including mood and anxiety disorders, fatigue, apathy, psychosis, cognitive impairment, dementia, sleep disorders and addictions, frequently complicate the course of the illness. The pathophysiologic features of these complications are multifaceted and include neuropathophysiologic changes of a degenerative disease, exposure to antiparkinsonian treatments and emotional reactions to having a disabling chronic illness. Changes in mental status have profound implications for the well-being of patients with Parkinson's disease and of their caregivers. Treatment is often efficacious but becomes a challenge in advanced stages of Parkinson's disease. In this article, we review the key clinical features of neuropsychiatric complications in Parkinson's disease as well as what is known about their epidemiologic characteristics, risk factors, pathophysiologic features and management.

CMAJ 2006;175(12):1545-52

$\mathrm{P}$ arkinson's disease is a progressive neurologic disorder affecting about 100 ooo Canadians. ${ }^{1}$ Although it is considered primarily a movement disorder, characterized by rest tremor, bradykinesia, rigidity and postural instability, the high prevalence of psychiatric complications suggests that Parkinson's disease is more accurately conceptualized as a neuropsychiatric disease. Neuropsychiatric disturbances - including mood and anxiety disorders, fatigue and apathy, psychosis, cognitive impairments, sleep disorders and addictions - can be part of the process of Parkinson's disease itself or can result from complex interactions between the progressive and widespread pathologic changes of the disease, emotional reactions to ParkinsonF ism and treatment-related side-effects. Neuropsychiatric complications are common. More than $60 \%$ of patients with Parkinson's disease report one or more psychiatric symptoms at some point in the course of their illness. ${ }^{2}$ These symptoms are often a significant source of disability and constitute some of the most difficult treatment challenges in advanced Parkinson's disease. ${ }^{3}$
In this article, we review the primary care approach to the recognition, management and prevention of neuropsychiatric disorders in patients with Parkinson's disease.

\section{Mood, fatigue and anxiety disorders}

\section{Depression}

Depression is one of the most common psychiatric disturbances reported by patients with Parkinson's disease. However, it is often underrecognized. Estimates of the overall prevalence vary considerably, but a figure of about $40 \%-45 \%$ in both sexes is generally accepted. ${ }^{2}$

Depression may occur at any stage of Parkinson's disease. Symptoms are similar to those experienced by adults in the general population (Box I). ${ }^{4}$ In Parkinson's disease, most patients experience mild-to-moderate depression, whereas major depression occurs reportedly less often. Depression can be particularly difficult to diagnose in patients with Parkinson's disease because of the clinical overlap between the 2 illnesses. Psychomotor slowing, concentration and sleeping difficulties occur frequently in Parkinson's disease, as do diminished appetite and sexual desire. Moreover, social withdrawal is common in Parkinson's disease, when patients become less able to participate or more uncomfortable with their appearance, tremors or dyskinesia. Nevertheless, compared with people who have depression but no Parkinson's disease, depressed patients with Parkinson's disease tend to experience more anxiety, brooding, irritability, cognitive deficits, pessimism and suicidal ideation without suicidal behaviour, although lower rates of guilt and self-blame. ${ }^{5}$ Symptoms favouring depression that may help in the differential diagnosis include early morning awakening, pervasive (more than 2 weeks) low mood with diurnal variation, and pessimistic thoughts about oneself, the world and the future. ${ }^{6}$ When in doubt, interviewing third parties is a valuable source of information about the patient's emotional state. Although the diagnosis of depression should be made clinically, use of the Beck Depression Inventory-I, ${ }^{7}$ a self-administered questionnaire, or the Hamilton Depression Rating Scale ${ }^{8}$ should be considered for screening for depression and measuring symptom severity. ${ }^{3}$

The cause of depressive disorder in Parkinson's disease is attributed to a complex combination of neurotransmitter (mainly dopamine, serotonin and norepinephrine) abnormal- 
ities. An allelic variation in serotonin transporters has been suggested to predispose to mood disorders. ${ }^{9}$ Alternatively, in many patients, there is some aspect of reactive depression, particularly at the time of initial diagnosis when learning that treatments are not curative.

\section{Management}

The first step in the successful management of depression in Parkinson's disease is to optimize dopaminergic therapy for improved motor symptoms (Box 2). Furthermore, levodopa, dopamine agonists and selegiline are believed to have mild antidepressant effects and have been studied as antidepressants. ${ }^{10}$

Psychosocial support, counselling and psychotherapy are also helpful, but further research is recommended. ${ }^{11}$ Individualized psychosocial counselling and structured physical therapy may help patients to identify their problems and concerns and to formulate appropriate coping strategies.

\section{Box 1: Diagnostic criteria of depressive disorder*}

Depression is defined as a pervasive pattern of depressed mood and/or loss of interest or pleasure causing clinically significant distress or impairment in social, occupational or other important areas of functioning.

Depressive disorder is diagnosed if the patient has 5 or more of the following symptoms during the same 2-week period and they represent a change from previous functioning (and at least one of the symptoms is either depressed mood, or loss of interest or pleasure):

Affective symptoms

- Depressed mood: persistent sad, anxious or "empty" mood

- Markedly diminished interest or loss of pleasure in hobbies and activities that were once enjoyed, including sex

- Feelings of hopelessness, pessimism

- Feelings of worthlessness or excessive or inappropriate guilt (which may be delusional)

- Anxiety

- Recurrent thoughts of death (not just fear of dying), recurrent suicidal ideation without a specific plan, or a suicide attempt or a specific plan for committing suicide

Psychomotor symptoms

- Psychomotor agitation (morbid increase in action or movement) or retardation (morbid slowing of action or movement)

- Apathy

- Restlessness, irritability

Cognitive symptoms

- Diminished ability to think, concentrate or remember

- Difficulty in making decisions, indecisiveness

Physical symptoms

- Decreased energy, fatigue, being "slowed down"

- Insomnia, early morning awakening or oversleeping

- Loss of appetite or weight loss, or overeating and weight gain

- Persistent physical symptoms (e.g., headaches, digestive disorders, chronic pain) that do not respond to treatment

*Based on DSM-IV-TR criteria ${ }^{4}$ and reorganized in relation to basic dimensions.
The relative efficacy and merit of various available antidepressant treatments in Parkinson's disease have received little study ${ }^{12}$ In clinical practice, the decision to initiate antidepressant therapy is based on many factors, including clinical findings, the probability of depressive symptoms worsening without therapy and the patient's likely acceptance. When in doubt, a psychiatric consult is recommended. Close communication between the physician treating the Parkinson's disease and the mental health team is especially important for the patient's care.

The classes of antidepressants prescribed to treat depression in adults in the general population - selective serotonin reuptake inhibitors (SSRIs), tricyclic antidepressants (TCAs) and serotonin-norepinephrine reuptake inhibitors (SNRIs) - are used to treat depression in patients with Parkinson's disease. Despite some reports of apparent exacerbation of parkinsonian symptoms ${ }^{13}$ there is little compelling evidence that SSRIs present any particular risk for patients with Parkinson's disease. Therefore, most clinicians use SSRIs as a firstline treatment. ${ }^{14}$ TCAs can also be useful, ${ }^{3}$ but difficulties tolerating them often lead to treatment discontinuation. The anticholinergic properties and cardiovascular effects of TCAs may be particularly troublesome for elderly people with Parkinson's disease. Furthermore, because an overdose can be lethal, special caution is needed in prescribing TCAs to suicidal patients. SNRIs have been reported in the treatment of depression in patients with Parkinson's disease, but clinical trials are required to determine their efficacy.

Antidepressants used to treat depression in patients with Parkinson's disease are listed in Box 2. The choice is based on the drug's pharmacologic profile and the patient's comorbidity, medication history and type of symptoms experienced. For example, patients with an anergic depression may be better suited to receive an antidepressant that is nonsedating or has a low sedating effect, whereas patients with a prominent sleep disorder may benefit more from fluvoxamine, mirtazapine or a TCA. In cases of prominent anxiety symptoms, the use of paroxetine, sertraline or venlafaxine should be considered as first-line options.

The antidepressant dose should be low initially and increased gradually. For monitoring the dose, the physician should examine vital signs, symptoms of depression, compliance with the antidepressant, side effects and drug interactions. Patients should be followed closely (e.g., weekly or biweekly) until their neuropsychiatric condition is stable. Major risk factors for side effects include advanced age, high medication doses, prolonged duration of antiparkinsonian treatment and polypharmacy. With respect to drug interactions, there is some concern about using SSRIs in patients taking selegeline because of the risk of serotonin syndrome, a rare but serious drug interaction. ${ }^{15}$

Electroconvulsive therapy is effective in treating depressive symptoms and has been found to provide transient improvement in motor function. ${ }^{16}$ Thus, patients with Parkinson's disease who have severe depression and whose condition is refractory to antidepressant therapy are candidates for electroconvulsive therapy. Use of repetitive transcranial magnetic stimulation, a less invasive method, has also been promising, ${ }^{17}$ but more research is needed. 


\section{Fatigue and apathy}

Difficulties in the diagnosis of depression arise not only in differentiating depression from parkinsonism but also in differentiating it from apathy and fatigue syndromes. The underlying pathophysiology of apathy and fatigue remains poorly understood. In contrast to the apathy seen in depression, apathy in nondepressed patients with Parkinson's disease is characterized by an isolated lack of motivation (i.e., no initiative), without anhedonia, hopelessness and low mood. Apathy has been reported by $12 \%-16 \%$ of patients with Parkinson's disease. ${ }^{2}$ Fatigue is a subjective sensation defined as an overwhelming sense of tiredness, lack of energy or feeling of exhaustion at any given time and has been reported by $42 \%$ of patients with Parkinson's disease. ${ }^{18}$ Both apathy and fatigue significantly reduce patients' quality of life.

\section{Management}

Evidence to guide the clinical management of apathy and fatigue is limited. However, clinical practice shows that educating patients and their caregivers about apathy and fatigue helps them to distinguish these symptoms from depression and laziness. To accomplish all daily activities, energy-saving principles, coaching, prompting and good sleep hygiene may decrease executive dysfunctions and fatigue. Also, improved control of the Parkinson's disease may help to alleviate apathy and fatigue. Introduction of dopamine agonists or methylphenidate ${ }^{19}$ have been proposed, but clinical benefits are frequently disappointing or limited by side effects. In most cases, antidepressants have no significant action on symptoms of apathy or fatigue and may cause unnecessary side effects.

\section{Anxiety}

Up to $40 \%$ of patients with Parkinson's disease experience clinically significant anxiety, including panic disorder, generalized anxiety and phobic disorders. This rate is higher than that in the general population and in groups of patients with similar physical disabilities (e.g., multiple sclerosis)..$^{5,20}$ Somatic symptoms include breathlessness, sweating, chest discomfort, gastralgia, restlessness and dizziness. Patients may experience fear of institutionalization, of going insane or of dying. The precise cause of anxiety disorders in patients with Parkinson's disease is unknown. Anxiety may be a psychological reaction to the

\section{Box 2: Management of depression in Parkinson's disease}

- Optimization of dopaminergic therapy

- Psychosocial support and counselling and specific psychotherapies (coping strategies, physical therapy)

- Antidepressant treatment

\begin{tabular}{llcc} 
Rate of titration* & $\begin{array}{c}\text { Dosing } \\
\text { frequency }\end{array}$ & $\begin{array}{c}\text { Daily dose } \\
\text { range, } \mathrm{mg} / \mathrm{d} \dagger\end{array}$ & $\begin{array}{c}\text { Remarkable } \\
\text { properties }\end{array}$ \\
\cline { 2 - 4 } First line & &
\end{tabular}

SSRI

\begin{tabular}{|c|c|c|c|c|}
\hline Citalopram & $10 \mathrm{mg}$ every $1-2 \mathrm{wk}$ & od or qhs & $10-20$ & Low sedation \\
\hline Fluoxetine & $10 \mathrm{mg}$ every $2-3 \mathrm{wk}$ & od & $10-20$ & No sedation \\
\hline Fluvoxamine & 50 mg every wk & qhs & $100-200$ & Sedation \\
\hline Paroxetine & $10 \mathrm{mg}$ every $1-2 \mathrm{wk}$ & od & $20-40$ & Low sedation, a \\
\hline Sertraline & $25 \mathrm{mg}$ every $1-2 \mathrm{wk}$ & od or qhs & $50-200$ & No sedation, an \\
\hline \multicolumn{5}{|l|}{ NRI } \\
\hline Mirtazapine & 15 mg every $2-3 w k$ & qhs & $15-30$ & Strong sedation \\
\hline Venlafaxine XR & 37.5 mg every wk & od & $75-150$ & No sedation, an \\
\hline upropionł & 100 mg every wk & $\begin{array}{l}150 \text { mg per dose } \\
\text { (before } 2 \mathrm{pm} \text { ) }\end{array}$ & $150-300$ & No sedation \\
\hline \multicolumn{5}{|l|}{ econd line } \\
\hline \multicolumn{5}{|l|}{ CA } \\
\hline Amitriptyline & $10-25 \mathrm{mg}$ every wk & qhs & $75-150$ & Strong sedation \\
\hline Nortriptyline & $10-25 \mathrm{mg}$ every $\mathrm{wk}$ & qhs & $50-75$ & Sedation \\
\hline
\end{tabular}

\section{- Electroconvulsive therapy}

Note: SSRI = selective serotonin reuptake inhibitor, SNRI = serotonin-norepinephrine reuptake inhibitor, TCA = tricyclic antidepressant, od $=$ once daily, qhs $=$ once daily at dinner or bedtime.

*Medication should be titrated slowly and as tolerated up to the dose that provides optimal benefit.

TOnce the lowest daily dose range is achieved, sufficient time (up to 3-5 wk) should be allowed to elapse before further dose increments. The optimal dose is achieved when no further improvement in depressive symptoms occurs and side effects are still judged to be manageable. The dose response varies considerably among patients; the doses listed above - based on literature data and on our clinical experience - serve only as a guide.

¥The mechanism of bupropion's antidepressant activity is unknown but appears to be mediated by noradrenergic (and possibly dopaminergic) rather than serotonergic mechanisms. 
symptoms of the Parkinson's disease; it may also be related to the neurochemical degenerative changes associated with the disease, with progressive decreases in dopamine, serotonin and norepinephrine levels. Severe anxiety may accompany the "off" phenomenon in patients with motor fluctuations in advanced stages of Parkinson's disease. Anxiety symptoms can surface before any motor symptoms are noted and may be an early manifestation of Parkinson's disease or a risk factor for Parkinson's disease. ${ }^{21}$

Because anxiety and depressive symptoms frequently coexist, a diagnosis of anxiety should prompt a screening for depression.

\section{Management}

The first-line pharmacologic treatment of anxiety in patients with Parkinson's disease has not been clearly established. Management typically follows that of treating anxiety in patients without the disease. When a time correlations exists with the "off" period, minimizing the "off" state is needed, before psychotropic agents are used. Patients need to be educated about the "off" state and reassured that even a prolonged "off" state will eventually improve. Providing psychological support, education and counselling to promote appropriate coping strategies contribute to the patient's well-being.

Patients may also benefit from short-term therapy with a benzodiazepine or buspirone. A benzodiazepine with a short half-life (e.g., alprazolam, lorazepam or oxazepam) is frequently prescribed, but because most patients with Parkinson's disease are elderly, side effects (oversedation, increased risk of falls, cognitive impairment) may compromise any anxiolytic gain. Thus, benzodiazepines should be used with caution and preferably for short periods. Formulations with a long half-life should be avoided. Buspirone has been found to be well tolerated at low doses (10-40 $\mathrm{mg} / \mathrm{d}$ ), but higher daily doses may worsen parkinsonism. ${ }^{22}$ Alternatively, some SSRIs or venlafaxine may be effective for treating anxiety. However, many specialists prefer using these agents only if depression is also present.

\section{Mood fluctuations and bipolar disorder}

Mood fluctuations (profound mood changes from depression to hypomania that can occur several times a day) have been estimated to occur in $7 \%-21 \%$ of patients with Parkinson's disease. ${ }^{23}$ They tend to be associated in time with motor fluctuations, in that patients experience low mood (more often a mixed depressive-anxious state) during the "off" period and normal or elevated mood (euphoria and hypomania) during the "on" phase. However, mood fluctuations may also occur without evident motor fluctuations in some patients. ${ }^{23}$

Bipolar disorder appears to be rare in Parkinson's disease. Development of manic symptoms has been described during the "on" phase, in association with anticholinergic therapy and as a side effect of pallidotomy or deep-brain stimulation.

\section{Management}

Adjustment of dopaminergic medications to minimize evident "on-off" fluctuations is a likely first step. Because no treatment trials of mood fluctuations and bipolar disorder in Parkinson's disease have been conducted, treatment is tailored to the individual patient. A psychiatric consultation is recommended. The use of anxiolytics and antipsychotics (quetiapine, clozapine) can be helpful but depend on individual needs and tolerability.

\section{Psychosis}

Psychosis affects $20 \%-40 \%$ of patients with Parkinson's disease. ${ }^{24}$ Various perceptual disorders occur in these patients, including sense of a presence, illusions or hallucinations (visual, auditory and tactile). ${ }^{25}$ More common in the evening, visual hallucinations are complex, usually of people and animals moving (sideways passage). At first, patients often maintain insight that the hallucinations are not real but later act as if they were. Paranoid delusions, often pathologic jealousy (e.g., spouse having sexual encounters with another person), can develop and typically cause distress and reduce quality of life.

Various hypotheses of the pathophysiology of psychosis in Parkinson's disease are under current investigation. Significant independent risk factors have been identified, including advanced age, prolonged disease duration and severity, cognitive impairment, depression and sleep disorders. Some studies have included as well the likely contribution of visual retinal and cortical sensory dysfunction. ${ }^{25,26}$ The long-held "continuum hypothesis" ${ }^{27}$ for drug-induced psychosis with antiparkinsonian drugs (particularly dopaminergic and anticholinergic agents), in which druginduced sleep disruption leads to vivid dreams and finally to hallucination and delirium, is now under review. ${ }^{24}$ Indeed, psychosis does not develop in all patients taking these drugs.

\section{Management}

A summary of the management of psychosis in Parkinson's disease is provided in Box 3. Management is difficult, since optimizing motor function with increasing doses of dopaminergic drugs typically precipitates psychosis, and antipsychotic drugs can worsen motor symptoms. When hallucinations arise without undue distress, especially if insight is preserved, support and counselling are often the only actions required. When hallucinations or delusions are frightening or insight is lost, and there is a risk of the patient acting out and injuring himself or herself or others, more robust interventions are essential.

The severity of the psychosis can be reduced through an effective treatment approach (Box 3). The first-line approach involves treating any reversible cause as one would for a delirium, lowering doses of or discontinuing nonessential medications, and simplifying the antiparkinsonian drug regimen. ${ }^{28}$ 
If attempts at simplifying the antiparkinsonian regimen result in an unacceptable worsening of motor function in the presence of persistent psychosis, a second-line approach based on antipsychotic drug therapy should be considered. Because of the risk of severe antipsychotic sensitivity reactions (characterized by a sudden onset of sedation, increased confusion, rigidity and immobility, with substantial reductions in survival), increased caution would seem appropriate for the use of antipsychotic agents in patients with Parkinson's disease. ${ }^{29} \mathrm{~A}$ consultation with a specialist is recommended. Typical antipsychotic agents all worsen motor symptoms and should not be used. Atypical antipsychotic agents are less likely to cause extrapyramidal side effects. Among them, quetiapine is the current first-line choice (on the basis of open-labelled studies ${ }^{30,31}$ ), at a starting dose of $12.5^{-25} \mathrm{mg} / \mathrm{d}$ at bedtime and a mean maintenance dose of about $75 \mathrm{mg} / \mathrm{d}$. Clozapine is most efficacious, ${ }^{32}$ at often low daily doses ( $12.5-50 \mathrm{mg} / \mathrm{d}$ ), but it is still considered by clinicians as a second-line choice because of the risk of agranulocytosis and the need for frequent monitoring of blood counts. Risperidone and olanzapine have been found to worsen Parkinson's disease and are not recommended. ${ }^{3}$

For patients with Parkinson's disease who have psychosis in the presence of cognitive impairment or dementia but are

Box 3: Management of psychosis in Parkinson's disease

- Psychosocial support for patients and caregivers

- Elimination of triggering factors

Infection (pneumonia, urinary tract infection, phlebitis)

Metabolic and electrolyte disturbances

Depression

Sleep disorders

Hearing and vision defects

- Simplification of complicated medication regimens

- Lower doses of or discontinue nonessential medications (mainly drugs with anticholinergic or sedative properties [e.g. anxiolytics, anticholinergics, mirtazapine, tricyclic antidepressants])

- Reduction or discontinuation of nonessential antiparkinsonian drugs (with monitoring of motor functions) in the following order:

Anticholinergic

Selegiline

Amantadine

Dopamine agonist

COMT inhibitor

Standard levodopa

- Addition of antipsychotic medication if psychosis is persistent and problematic

Quetiapine (first line)

Clozapine (with close monitoring of blood count)

- Addition of cholinesterase inhibitor before antipsychotic drug (if the psychosis occurs in a patient with cognitive impairment or dementia and there is no risk of injury to the patient or others)

Note: COMT = catechol-0-methyltransferase. not at risk of injuring themselves or others, the use of a cholinesterase inhibitor may be considered before the use of an antipsychotic agent. ${ }^{33}$

\section{Cognitive impairment and dementia}

About $50 \%$ of patients with Parkinson's disease without dementia are found to have, on standardized cognitive tests, mild cognitive impairment. The cognitive impairment can present early in the course of the disease and sometimes precedes the development of memory deficits. ${ }^{34}$ The types of impairment reported in the literature are heterogeneous but include mainly impairments in executive (i.e., impaired planning and working memory), visuo-spatial, attentional and language functioning. ${ }^{34}$

Dementia occurs later in the disease process in up to $30 \%$ of people with Parkinson's disease. ${ }^{34}$ Neuropsychiatric symptoms are more common in patients who have Parkinson's disease with dementia (PDD). ${ }^{35}$ To date, there are no specific criteria for diagnosing dementia in Parkinson's disease. Currently, generic criteria such as those in the DSM-IV are applied ("dementia due to other general medical conditions"). Theoretically, patients with Parkinson's disease can have any type of dementia, as happens in the rest of the population. Distinguishing PDD from dementia with Lewy bodies is complex and beyond the scope of this review, even though their clinical courses and treatments may be different.

The assessment of patients for cognitive impairment can be done to some extent in the office with the use of the MiniMental State Examination. ${ }^{36}$ Alternatively, additional neurologic and neuropsychologic consultations could be helpful. Camicioli and Gauthier have proposed several tests to study cognition and neuropsychologic features of PDD. ${ }^{37}$

Although not well established, deficits of multiple neurotransmitter systems, including dopaminergic, cholinergic, serotonergic and noradrenergic transmitters, are believed to be involved in cognitive symptoms of PDD. ${ }^{38}$ The progressive loss of dopaminergic functioning in the substantia nigra (interfering with frontal subcortical dopaminergic neurons) $)^{39}$ and the loss of cholinergic cells in the nucleus basalis of Meynert are thought to probably lead to major cognitive impairment and PDD. ${ }^{40}$ Lastly, cortical and subcortical Lewy bodies may also be causative of dementia in Parkinson's disease, but this link is controversial. ${ }^{41}$

\section{Management}

Treatment approaches in PDD are mostly symptomatic. First, exacerbating factors of cognitive impairment should be eliminated (infections, dehydration, metabolic factors). Also, any nonessential medications (e.g., drugs with anticholinergic or sedative properties) should be discontinued. The use of a cholinesterase inhibitor may be helpful in improving cognitive function and reducing neuropsychiatric symptoms in dementia associated with Parkinson's disease. ${ }^{42}$ However, a recent Cochrane review ${ }^{43}$ identified only I published randomized, double-blind, placebo-controlled study showing a benefit: in a large population of patients with PPD $(n=54 \mathrm{I})$, rivastigmine 
was found to be clinically beneficial in $19.8 \%$ of cases. ${ }^{44}$ Findings from other small controlled studies of donezepil ${ }^{38,45,46}$ and an open-label study of galantamine ${ }^{47}$ for the treatment of PDD have suggested that these agents may produce a modest cognitive benefit. Further randomized trials with sufficient patient populations are needed to draw definitive conclusions.

\section{Sleep disorders}

Sleep disorders are common in Parkinson's disease, affecting $60 \%-98 \%$ of patients. ${ }^{48}$ They may occur as a result of the Parkinson's disease itself or as a result of medications or comorbidities (mood disorders, cognitive impairment, pain). ${ }^{28}$ The many types of sleep disorders that affect patients can be classified into 2 main categories: dyssomnia (insomnia or hypersomnia) and parasomnia (Table I).

Insomnia is commonly defined as a perception of insufficient or poor-quality sleep that leads to a feeling of being unrefreshed. It includes difficulties in initiating sleep, sleep

Table 1: Common sleep disorders in Parkinson's disease

\begin{tabular}{|c|c|}
\hline Sleep disorder & Management \\
\hline \multicolumn{2}{|l|}{ Dyssomnia* } \\
\hline \multicolumn{2}{|l|}{ Insomnia } \\
\hline Idiopathic insomnia & Hypnotic medication \\
\hline $\begin{array}{l}\text { Motor manifestations of Parkinson's } \\
\text { disease (stiffness, inability to move, } \\
\text { cramps, dystonia, pain) }\end{array}$ & $\begin{array}{l}\text { Adjustment of dopaminergic medication; } \\
\text { analgesic; use of satin sheets (to relieve } \\
\text { stiffness, pain) }\end{array}$ \\
\hline Nocturnia & $\begin{array}{l}\alpha \text {-Adrenergic blocker; } 5 \alpha \text {-reductase } \\
\text { inhibitor }\end{array}$ \\
\hline $\begin{array}{l}\text { Restless legs syndrome, periodic limb } \\
\text { movement disorder }\end{array}$ & $\begin{array}{l}\text { Adjustment of dopaminergic medication; } \\
\text { anticonvulsant }\end{array}$ \\
\hline $\begin{array}{l}\text { Breathing-related disorder (obstructive } \\
\text { sleep apnea syndrome) }\end{array}$ & Weight loss; CPAP \\
\hline \multicolumn{2}{|l|}{ Hypersomnia } \\
\hline Excessive daytime sleepiness & $\begin{array}{l}\text { Adjustment of dopaminergic medication; } \\
\text { caffeine; methylphenidate; modafinil }\end{array}$ \\
\hline Sleep attacks & $\begin{array}{l}\text { Adjustment of dopaminergic medication; } \\
\text { modafinil }\end{array}$ \\
\hline \multicolumn{2}{|l|}{ Parasomnia $†$} \\
\hline $\begin{array}{l}\text { Arousal disorder (vivid dreams, sleep } \\
\text { terror disorder) }\end{array}$ & Adjustment of dopaminergic medication \\
\hline $\begin{array}{l}\text { Sleep-wake transition disorder } \\
\text { (e.g., nocturnal vocalizations, sleep } \\
\text { talking, hypnagogic jerks) }\end{array}$ & Adjustment of dopaminergic medication \\
\hline $\begin{array}{l}\text { REM sleep disorder (nightmare disorder, } \\
\text { REM behaviour disorder) }\end{array}$ & $\begin{array}{l}\text { Adjustment of dopaminergic medication; } \\
\text { clonazepam }\end{array}$ \\
\hline \multicolumn{2}{|l|}{$\begin{array}{l}\text { Sleep disorder related to psychiatric } \\
\text { disorder }\end{array}$} \\
\hline Anxiety, depression & Anxiolytic; antidepressant \\
\hline Cognitive impairment, dementia & Cholinesterase inhibitor \\
\hline Psychosis & Antipsychotic (quetiapine, clozapine) \\
\hline
\end{tabular}

Note: $\mathrm{REM}=$ rapid eye movement, $\mathrm{CPAP}$ = continuous positive airway pressure.

*Primary sleep disorder of initiating and maintaining sleep or excessive sleepiness.

†Sleep disorder of arousal, partial arousal or sleep-stage transition. It represents an episodic disorder in sleep rather than a disorder of sleep. May be induced or exacerbated by sleep. fragmentation and early morning awakening. A variety of processes may interfere with sleep initiation and maintenance. Motor manifestations of Parkinson's disease (stiffness, inability to move in bed, tremor, dystonic movements, cramps) and nocturnia are often responsible for insomnia. Psychiatric disorders (depression, anxiety, hallucinations) and dementia can interfere with sleep's quality. Moreover, other sleep disorders (restless legs syndrome, periodic limb movement disorder, obstructive sleep apnea syndrome) and certain medications are also found to disturb normal sleep. ${ }^{48}$

Hypersomnia refers to excessive daytime sleepiness and sleep attacks. Excessive daytime sleepiness is frequent (affects $20 \%-50 \%$ of patients with Parkinson's disease) and refers to a disabling tendency to nod or fall asleep in various situations that interferes with familial, professional and social life. The experience of sleep attacks, on the other hand, is rare (affects I\%-27\% of patients with Parksinson's disease) and is defined as an "event of sudden, irresistible and overwhelming sleepiness that occurs without sleepiness and is not preceded by being sleepy"; such attacks occur during stimulating life circumstances such as eating, walking or, of more dangerous consequences, driving a car. ${ }^{49}$

The reasons for excessive daytime sleepiness in Parkinson's disease are multifactorial and include difficulties with sleeping at night, the disease process itself, the impact of dopaminergic medications and other medications (e.g., psychotropic agents), and coexisting conditions such as depression, dementia or sleep apnea. Sleep attacks have been associated with all dopamine agonists and sometimes with levodopa alone. ${ }^{49}$

Parasomnia represents signs and symptoms that occur during sleep. Many patients with Parkinson's disease report vivid dreams, nocturnal hallucinosis, nightmares, night terrors, nocturnal vocalizations, sleep walking, sleep talking, panic attacks and rapid eye movement (REM) behaviour disorder (RBD). RBD is a disturbing clinical syndrome in which patients lack the normal muscle atonia associated with REM sleep and may be seen to "act out their dreams" with kicking, grabbing, yelling, shouting, falling out of bed or even jumping out of bed. The occurrence of RBD may actually precede the onset of motor symptoms in patients with Parkinson's disease and may occur in up to $33 \%$ of patients. ${ }^{50}$

\section{Management}

Treatment depends on the proper identification of the factors involved in disturbed sleep (Table I). Sleep hygiene 
should be thoroughly evaluated (Box 4). Specific sleep disorders should be investigated in clinical practice and, if necessary, in a sleep laboratory. Effects of medications must all be assessed in any patient with Parkinson's disease who has disturbed sleep or daytime sleepiness. Lastly, it is important to discuss with family members and caregivers sleep disorders associated with Parkinson's disease.

\section{Addiction and related disorders}

Parkinson's disease is treated primarily with drugs that attempt to restore cerebral dopaminergic neurotransmission. The dopaminergic system (particularly dopamine $\mathrm{D}_{2}$ receptors, the nucleus accumbens and the mesolimbic pathway) is implicated in various kinds of addictions through the brain's reward mechanisms. ${ }^{51}$ Therefore, dopaminergic medications may lead to secondary behavioural disorders.

\section{Substance abuse and dependence}

To our knowledge, there are no formal studies of substance abuse or dependence in Parkinson's disease. However, severe dopamine addiction (or levodopa misuse) is now well described. ${ }^{51}$ Patients with this addiction tend to take increasing quantities of dopaminergic drugs as psychostimulants, despite severe drug-induced dyskinesia. In addition to worsening motor function, mood disorders with drug-induced hypomania or manic psychosis may also develop. Dopaminergic therapy may be associated with other neuropsychiatric symptoms, including punding (repetitive, purposeless behaviours, such as dismantling electrical equipment, which can also be seen in amphetamine or cocaine addiction), drug hoarding and drug-seeking behaviours.

Severe dopamine addiction can lead to impairment of occupational and social functioning. Its management is difficult, but generally it is best treated with gradual reduction of dopaminergic drug doses in association with symptomatic treatment of psychiatric symptoms.

\section{Pathologic gambling}

Pathologic gambling is an impulse control disorder defined as a failure to resist gambling impulses despite severe personal, familial or vocational losses. ${ }^{4}$ Its prevalence is unknown, but it may affect $\mathrm{I} .5 \%$ of patients taking pramipexole and about $0.3 \%$ of those taking other dopamine agonists. ${ }^{52}$

The pathogenesis of pathologic gambling is poorly understood. The disorder may not be specific to any agent but, rather, to the total dopaminergic load. ${ }^{53}$ Some have stated that the risk of pathologic gambling is similar for patients taking ropinirole, pergolide and pramipexole,$^{54}$ whereas others have argued that the disorder occurs mainly in patients taking pramipexole. ${ }^{55}$

\section{Hypersexuality and sexual deviation}

Resurrection of sexual interest is a well-known side effect of dopaminergic therapy in patients with Parkinson's disease. ${ }^{56}$ Less well reported, however, are occurrences of hypersexuality (e.g., constant desire for sexual intercourse to the point of partner exhaustion, and increased use of Internet sex chat rooms, pornographic materials or prostitutes) and sexual deviation (zoophilia, ${ }^{57}$ transvestic fetishism)..$^{58}$ These disorders often occur in patients without a prior psychiatric history or obvious cognitive deficits. ${ }^{59} \mathrm{~A}$ recent review found that paraphilia accounted for $3 \%$ of all neuropsychiatric complications of drug treatment of Parkinson's disease. ${ }^{60}$ The cause of this compulsive behaviour is poorly understood, but it may be related either to increased sexual drive (over a return to normal) or lack of sexual impulse control. Both are dependent on dopaminergic regulation. However, in some cases, mainly when cognitive impairment complicates Parkinson's disease, sexual compulsive behaviours may be related to a lack of behavioural inhibition.

\section{Management}

Gambling, hypersexuality and sexual deviation are behaviours that are not promptly diagnosed because they tend to be hidden by patients and clinicians may not be familiar with them in association with Parkinson's disease. If not identified and treated, impulsive behaviours may result in significant distress, marital conflicts, financial difficulties and even legal procedures. Thus, all patients receiving therapy with dopaminergic medications should be advised and monitored closely for impulse control disorders. These disorders are often dose dependent and subside when the dopaminergic dose is reduced or the therapy is discontinued. Counselling of patients, family and caregivers is warranted.

\section{Summary}

Neuropsychiatric complications in Parkinson's disease are common and associated with increased disability, reduced quality of life of patients and caregiver distress. Early recognition of non-motor symptoms appears to be essential. The pathophysiology of neuropsychiatric complications in Parkinson's disease is multifaceted and includes neuropathophysiologic changes of a degenerative disease, exposure to antiparkinsonian medications and emotional reactions to having a disabling, chronic illness. Treatment is often efficacious but can be challenging. A multidisciplinary approach is important for patients and their caregivers. 
This article has been peer reviewed.

From the Alzheimer's Disease Research Unit, McGill Centre for Studies in Aging, Douglas Hospital, Verdun, Que. (Ferreri, Agbokou, Gauthier), and the Department of Psychiatry, Montreal Neurological Institute and Hospital, McGill University Health Centre, Montréal, Que. (Ferreri, Agbokou)

Competing interests: None declared for Florian Ferreri and Catherine Agbokou. Serge Gauthier has received consultancy fees, research grants and speaker fees from Janssen-Cilag, Lundbeck, Novartis and Pfizer.

Contributors: Florian Ferreri and Catherine Agbokou conceived and wrote this article. All of the authors critically revised the article and approved the final version submitted for publication.

Acknowledgement: We thank Dr. Ghislaine Savard of the Department of Psychiatry, Montreal Neurological Institute and Hospital, for her critical review of the article and her valuable comments.

\section{REFERENCES}

I. Guttman M, Kish SJ, Furukawa Y. Current concepts in the diagnosis and management of Parkinson's disease. CMAJ 2003; I68(3):293-30I.

2. Aarsland D, Larsen JP, Lim NG, et al. Range of neuropsychiatric disturbances in patients with Parkinson's disease. J Neurol Neurosurg Psychiatry 1999;67:492-6.

3. Miyasaki JM, Shannon K, Voon V, et al. Practice Parameter: evaluation and treatment of depression, psychosis, and dementia in Parkinson disease (an evidencebased review): report of the Quality Standards Subcommittee of the American Academy of Neurology. Neurology 2006;66:996-1002.

4. American Psychiatric Association. Diagnostic and statistical manual of mental disorders. 4th ed. (text revision). Washington: American Psychiatric Association; $200 \mathrm{I}$.

5. Schiffer RB, Kurlan R, Rubin A, et al. Evidence for atypical depression in Parkinson's disease. Am J Psychiatry ig88;145:1020-2.

6. Rickards H. Depression in neurological disorders: Parkinson's disease, multiple sclerosis, and stroke. J Neurol Neurosurg Psychiatry 2005;76(Suppl I):i48-52.

7. Leentjens AF, Verhey FR, Luijckx GJ, et al. The validity of the Beck Depression Inventory as a screening and diagnostic instrument for depression in patients with Parkinson's disease. Mov Disord 2000;15:I22I-4.

8. Leentjens AF, Verhey FR, Lousberg R, et al. The validity of the Hamilton and Montgomery-Asberg depression rating scales as screening and diagnostic tools for depression in Parkinson's disease. Int J Geriatr Psychiatry 2000;15:644-9.

9. Mossner R, Henneberg A, Schmitt A, et al. Allelic variation of serotonin transporter expression is associated with depression in Parkinson's disease. Mol Psychiatry 2001;6:350-2.

Io. Maricle RA, Nutt JG, Valentine RJ, et al. Dose-response relationship of levodopa with mood and anxiety in fluctuating Parkinson's disease: a double-blind, placebocontrolled study. Neurology i995;45:1757-60.

II. Cole K, Vaughan FL. The feasibility of using cognitive behaviour therapy for depression associated with Parkinson's disease: a literature review. Parkinsonism Relat Disord 2005;11:269-76.

I2. Weintraub D, Morales KH, Moberg PJ, et al. Antidepressant studies in Parkinson's disease: a review and meta-analysis. Mov Disord 2005;20:1I6I-9.

I3. Richard IH, Maughn A, Kurlan R. Do serotonin reuptake inhibitor antidepressants worsen Parkinson's disease? A retrospective case series. Mov Disord I999;I4:I55-7.

I4. Mendis T, Suchowersky O, Lang A, et al. Management of Parkinson's disease: a review of current and new therapies. Can J Neurol Sci 1999;26:89-103.

I5. Richard IH, Kurlan R, Tanner C, et al. Serotonin syndrome and the combined use of deprenyl and an antidepressant in Parkinson's disease. Parkinson Study Group. Neurology 1997;48:1070-7.

I6. Moellentine C, Rummans T, Ahlskog JE, et al. Effectiveness of ECT in patients with parkinsonism. JNeuropsychiatry Clin Neurosci 1998;10:187-93.

17. Fregni F, Simon DK, Wu A, et al. Non-invasive brain stimulation for Parkinson's disease: a systematic review and meta-analysis of the literature. J Neurol Neurosurg Psychiatry 2005;76:I6I4-23

18. Schwartz JE, Jandorf L, Krupp LB. The measurement of fatigue: a new instrument. J Psychosom Res 1993;37:753-62.

I9. Chatterjee A, Fahn S. Methylphenidate treats apathy in Parkinson's disease. J Neuropsychiatry Clin Neurosci 2002;I4:46I-2.

20. Richard IH, Schiffer RB, Kurlan R. Anxiety and Parkinson's disease. J Neuropsychiatry Clin Neurosci 1996;8:383-92.

2I. Weisskopf MG, Chen H, Schwarzschild MA, et al. Prospective study of phobic anxiety and risk of Parkinson's disease. Mov Disord 2003;18:646-5I.

22. Ludwig CL, Weinberger DR, Bruno G, et al. Buspirone, Parkinson's disease, and the locus ceruleus. Clin Neuropharmacol I986;9:373-8.

23. Richard IH, Frank S, McDermott MP, et al. The ups and downs of Parkinson disease: prospective study of mood and anxiety fluctuations. Cogn Behav Neurol 2004;17:20I-7.

24. Papapetropoulos S, Mash DC. Psychotic symptoms in Parkinson's disease. From description to etiology. J Neurol 2005;252:753-64.

25. Fenelon G, Mahieux F, Huon R, et al. Hallucinations in Parkinson's disease: prevalence, phenomenology and risk factors. Brain 2000;123:733-45.
26. Holroyd S, Currie L, Wooten GF. Prospective study of hallucinations and delusions in Parkinson's disease. J Neurol Neurosurg Psychiatry 2001;70:734-8.

27. Moskovitz C, Moses H III, Klawans HL. Levodopa-induced psychosis: a kindling phenomenon. Am J Psychiatry I978;135:669-75

28. Olanow CW, Watts RL, Koller WC. An algorithm (decision tree) for the management of Parkinson's disease (2001): treatment guidelines. Neurology 2001;56 (Suppl 5):SI-S88.

29. Aarsland D, Perry R, Larsen JP, et al. Neuroleptic sensitivity in Parkinson's disease and parkinsonian dementias. J Clin Psychiatry 2005;66:633-7.

30. Fernandez HH, Trieschmann ME, Burke MA, et al. Long-term outcome of quetiapine use for psychosis among Parkinsonian patients. Mov Disord 2003;18:510-4.

31. Juncos JL, Roberts VJ, Evatt ML, et al. Quetiapine improves psychotic symptoms and cognition in Parkinson's disease. Mov Disord 2004;19:29-35.

32. Friedman JH, Factor SA. Atypical antipsychotics in the treatment of drug-induced psychosis in Parkinson's disease. Mov Disord 2000;15:20I-II.

33. Poewe W. Treatment of dementia with Lewy bodies and Parkinson's disease dementia. Mov Disord 2005;20(Suppl I2):S77-82.

34. Camicioli R, Fisher N. Progress in clinical neurosciences: Parkinson's disease with dementia and dementia with Lewy bodies. Can J Neurol Sci 2004;3I:7-2I.

35. Aarsland D, Bronnick K, Ehrt U, et al. Neuropsychiatric symptoms in patients with PD and dementia: Frequency, profile and associated caregiver stress. J Neurol Neurosurg Psychiatry [Epub ahead of print 2006 July 4]. Available: http://jnnp.bmjjournals .com/cgi/rapidpdf/jnnp.2005.083II3vi.pdf (accessed 2006 Oct 6).

36. Folstein MF, Folstein SE, McHugh PR. "Mini-mental state." A practical method for grading the cognitive state of patients for the clinician. J Psychiatr Res 1975;12:189-98.

37. Camicioli R, Gauthier S. Guidelines for randomized clinical studies in Parkinson's disease with dementia and dementia with Lewy bodies. Can J Neurol Sci. In press.

38. Leroi I, Brandt J, Reich SG, et al. Randomized placebo-controlled trial of donepezil in cognitive impairment in Parkinson's disease. Int J Geriatr Psychiatry 2004;I9:I-8.

39. Dubois B, Pillon B. Cognitive deficits in Parkinson's disease. J Neurol 1997;244:2-8.

40. Nakano I, Hirano A. Parkinson's disease: neuron loss in the nucleus basalis without concomitant Alzheimer's disease. Ann Neurol I984;15:415-8.

4I. McKeith IG, Dickson DW, Lowe J, et al; Consortium on DLB. Diagnosis and management of dementia with Lewy bodies: third report of the DLB Consortium [published erratum in Neurology 2005;65:1992]. Neurology 2005;65:1863-72.

42. Feldman HH, Gauthier S, Chertkow H, et al. Progress in clinical neurosciences: Canadian guidelines for the development of antidementia therapies: a conceptual summary. Can J Neurol Sci 2006;33:6-26.

43. Maidment I, Fox C, Boustani M. Cholinesterase inhibitors for Parkinson's disease dementia [review]. Cochrane Database Syst Rev 2006;(I):CDoo4747.

44. Emre M, Aarsland D, Albanese A, et al. Rivastigmine for dementia associated with Parkinson's disease. N Engl J Med 2004;351:2509-I8.

45. Aarsland D, Laake K, Larsen JP, et al. Donepezil for cognitive impairment in Parkinson's disease: a randomised controlled study. J Neurol Neurosurg Psychiatry 2002;72:708-I2

46. Ravina B, Putt M, Siderowf A, et al. Donepezil for dementia in Parkinson's disease: a randomised, double blind, placebo controlled, crossover study. J Neurol Neurosurg Psychiatry 2005;76:934-9.

47. Aarsland D, Hutchinson M, Larsen JP. Cognitive, psychiatric and motor response to galantamine in Parkinson's disease with dementia. Int J Geriatr Psychiatry 2003 I8:937-4I.

48. Adler CH, Thorpy MJ. Sleep issues in Parkinson's disease. Neurology 2005;64 (Suppl 3):SI2-20.

49. Arnulf I. Excessive daytime sleepiness in parkinsonism. Sleep Med Rev 2005;9: I85-200.

50. Postuma RB, Lang AE, Massicotte-Marquez J, et al. Potential early markers of Parkinson disease in idiopathic REM sleep behavior disorder. Neurology 2006;66:845-5I.

5I. Lawrence AD, Evans AH, Lees AJ. Compulsive use of dopamine replacement therapy in Parkinson's disease: Reward systems gone awry? Lancet Neurol 2003;2:595-604

52. Stocchi F. Pathological gambling in Parkinson's disease. Lancet Neurol 2005;4:590-2.

53. Morgan JC, Iyer SS, Sethi KD. Impulse control disorders and dopaminergic drugs [letter]. Arch Neurol 2006;63:298-9.

54. Lu C, Bharmal A, Suchowersky O. Gambling and Parkinson disease. Arch Neuro 2006;63:298.

55. Dodd ML, Klos KJ, Bower JH, et al. Pathological gambling caused by drugs used to treat Parkinson disease. Arch Neurol 2005;62:1377-8I.

56. Barbeau A. L-dopa therapy in Parkinson's disease: a critical review of nine years' experience. $C M A J$ I969;10I:59-68.

57. Fernandez HH, Durso R. Clozapine for dopaminergic-induced paraphilias in Parkinson's disease. Mov Disord i998;13:597-8.

58. Riley DE. Reversible transvestic fetishism in a man with Parkinson's disease treated with selegiline. Clin Neuropharmacol 2002;25:234-7.

59. Klos KJ, Bower JH, Josephs KA, et al. Pathological hypersexuality predominantly linked to adjuvant dopamine agonist therapy in Parkinson's disease and multiple system atrophy. Parkinsonism Relat Disord 2005;II:38I-6.

6o. Cummings JL. Behavioral complications of drug treatment of Parkinson's disease. JAm Geriatr Soc 1991;39:708-16.

Correspondence to: Dr. Serge Gauthier, McGill Centre for Studies in Aging, 6825 Blvd. LaSalle, Verdun QC $\mathrm{H}_{4} \mathrm{H}_{\mathrm{I}} \mathrm{R}_{3}$;

serge.gauthier@mcgill.ca 